\title{
Key Markers of mTORC1-Dependent and mTORC1-Independent Signaling Pathways Regulating Protein Synthesis in Rat Soleus Muscle During Early Stages of Hindlimb Unloading
}

\author{
Timur Mirzoev Sergey Tyganov Natalia Vilchinskaya Yulia Lomonosova
} Boris Shenkman

Myology Laboratory, Institute of Bio-medical Problems RAS, Moscow, Russian Federation

\section{Key Words}

Soleus muscle $・$ Hindlimb unloading $\bullet$ Protein synthesis $\bullet$ Signaling pathways $\bullet$ rRNA

\begin{abstract}
Background/Aims: The purpose of the study was to assess the amount of rRNA and phosphorylation status of the key markers of mTORC1-dependent (70s6k, 4E-BP1) and mTORC1-independent (GSK-3ß, AMPK) signaling pathways controlling protein synthesis in rat soleus during early stages of mechanical unloading (hindlimb suspension (HS) for 1-, 3- and 7 days). Methods: The content of the key signaling molecules of various anabolic signaling pathways was determined by Western-blotting. The amount of $28 \mathrm{~S}$ rRNA was evaluated by RTPCR. The rate of protein synthesis was assessed using in-vivo SUnSET technique. Results: HS for 3 and 7 days induced a significant $(p<0.05)$ decrease in the rate of global protein synthesis in soleus muscle in comparison with control. HS within 24 hours resulted in a significant $(p<0.05)$ decrease in $\mathrm{p}-4 \mathrm{E}-\mathrm{BP} 1$ content, $\mathrm{p}-\mathrm{AMPK}$ content and increase in $\mathrm{p}-\mathrm{p} 70$ s6k content in rat soleus muscle. Following three days of HS the content of $p$-AKT was decreased $(p<0.05)$. After 7 days of HS the phosphorylation level of AKT and GSK-3beta was significantly reduced $(p<0.05)$ compared to control. We also observed a significant decrease in the amount of $28 \mathrm{~S}$ rRNA in rat soleus following 1, 3 and 7 days of HS. Conclusion: Taken together, the results of our study suggest that a decline in the global rate of protein synthesis in rat soleus during early stages of simulated microgravity is associated with impaired ribosome biogenesis as well as reduced activity of mTORC1-independent signaling pathways.
\end{abstract}

\section{Introduction}

It is well known that mechanical unloading results in a significant atrophy of mammalian postural muscles such as soleus [1]. In a number of human and animal studies

Dr. Timur Mirzoev

KARGER
Institute of Bio-medical Problems RAS, Myology Laboratory

123007, Khoroshevskoe shosse 76A, Moscow, (Russian Federation)

Tel.+7 49919563 10, Fax +7 49919522 53, E-Mail tmirzoev@yandex.ru 
it has been shown that disuse-induced muscle atrophy is associated with a decrease in the rate of protein synthesis and an increase in proteolysis [2-6]. Our work was focused on the investigation of molecular mechanisms controlling mRNA translation in the unloaded rat soleus muscle. Previously it was shown that mechanical unloading leads to a decrease in the rate of protein synthesis in rat soleus muscle both in vivo [7] and in vitro [8, 9]. It is currently believed that the regulation of protein synthesis in skeletal muscle in response to altered mechanical load (or the level of hormones, amino acids) occurs at the level of cap-dependent translation initiation $[10,11]$. IGF-1/AKT/mTORC1 is a canonical signaling pathway regulating protein synthesis at the level of translation initiation. The main effectors of this pathway are ribosomal protein kinase p70 (p70s6k) and translation initiation factor $4 \mathrm{E}$ binding protein (4E-BP1) [12]. In addition, translation initiation can be regulated via glycogen synthase kinase $3 \beta$ (GSK-3 $\beta$ ), which is a key element of AKT/GSK-3 $\beta /$ eIF2B signaling pathway. Protein kinase B (AKT) can phosphorylate and inhibit GSK-3 $\beta$, thereby activating translation initiation factor $2 \mathrm{~B}$ (eIF2B) [12]. At the same time GSK3 $\beta$ may be phosphorylated and inhibited by other kinases (for instance, by protein kinase A, integrinlinked kinase) [13]. It is important to note, that mTORC1-signaling can be regulated via adenosine monophosphate-activated protein kinase (AMPK), since AMPK activation can lead to a decrease in mTOR activity $[14,15]$. It is also known that eukaryotic elongation factor 2 (eEF2) plays an important role in the regulation of protein synthesis at the level of elongation of mRNA translation. eEF2 is able to inhibit translation elongation being phosphorylated on the Thr56 residue by eEF2 kinase [16]. It is worth noting that apart from regulation of translation initiation and elongation (i.e. translational efficiency), protein synthesis also depends on translational capacity, the main component of which is ribosome biogenesis $[17,18]$. One of the key markers of ribosome biogenesis is $28 \mathrm{~S}$ rRNA.

To date, there are a lot of reports concerning the phosphorylation status of the key markers of signaling pathways regulating protein synthesis in the rodent soleus muscle after 10, 14 or more days of gravitational unloading/immobilization. For example, it has been shown that 14-day HS induces a significant reduction in phosphorylated AKT (Ser473) $[19,20]$, p70s6k (Thr389) [19-21] and 4E-BP1 [19] in rat soleus muscle. At the same time, some authors did not find an increase in phosphorylated p70s6k (Thr389) in soleus after 10 days of mechanical unloading [22]. Van der Velden co-authors did not observe any changes in the phosphorylation status of both AKT (Ser473) and GSK-3 $\beta$ (Ser9) in soleus of mice following 14-day HS [23]. However, White et al. reported a decrease in AKT and GSK-3 $\beta$ phosphorylation in rat soleus muscle after 2-week unloading [24]. Previously we demonstrated that 3-day hindlimb unloading led to a significant increase in eEF2 phosphorylation on Thr 56 in rat soleus [25]. As for ribosome biogenesis during disuseinduced atrophy, Bajotto and colleagues found a decrease in the amount of $18 \mathrm{~S}+28 \mathrm{~S}$ rRNAs in soleus muscle after 6 days of HS [26]. However, in the available literature there is a lack of systematic data describing ribosome biogenesis, as well as the activity of the key markers of anabolic signaling pathways in mammalian postural muscle during the early stages of mechanical unloading. Therefore, the aim of our study was to assess the amount of 28S rRNA as well as the activity of different signal transduction pathways that regulate protein synthesis in rat soleus muscle during the early periods (1, 3 and 7 days) of mechanical unloading. Furthermore, we hypothesized that a decrease in the rate of protein synthesis in rat soleus muscle during the early stages of unloading may not be accompanied by a downregulation of the mTORC1-dependent pathways.

\section{Materials and Methods}

Animals and hindlimb suspension

All procedures with the animals were approved by the Biomedicine Ethics Committee of the Institute of Bio-medical Problems of the Russian Academy of Sciences (protocol no. 351, 10.02.2014). Animals were housed in a temperature-controlled room on a 12:12-h light-dark cycle with food pellets and water provided 
ad libitum. Unloading of the hindlimbs was induced by using a standard rodent hindlimb suspension/ unloading model [27]. Twenty-eight adult male Wistar rats weighing $220 \pm 5 \mathrm{~g}$, were randomly divided into 4 groups (7 animals in each group): Control (vivarium cage control), 1HS (HS for $24 \mathrm{~h}$ ), 3HS (HS for 3 days), 7HS (HS for 7 days). Prior to all surgical procedures, the animals were anaesthetized with an intraperitoneal injection of sodium pentobarbital $(50 \mathrm{mg} / \mathrm{kg}$ ). After the experimental procedures, the rats were euthanized by a sodium pentobarbital overdose. Soleus muscles were collected with standardized dissection methods, weighed, frozen in liquid nitrogen, and stored at $-80^{\circ} \mathrm{C}$.

\section{SUnSET technique for measuring the rate of protein synthesis}

SUnSET (surface sensing of translation) is a nonradioactive technique that allows to measure protein synthesis in vivo in skeletal muscle. This technique involves the use of the antibiotic puromycin (a structural analog of tyrosyl-tRNA), and anti-puromycin antibodies to detect the amount of puromycin incorporation into nascent peptide chains [28]. It was shown that when puromycin is used at low concentrations (40 $\mathrm{nmol} / \mathrm{g}$ ), the accumulation of puromycin-conjugated peptides accurately reflects the rate of protein synthesis [29, 30]. SUnSET technique uses standard Western blotting and immunohistochemical technologies to visualize and quantify in vivo rates of protein synthesis [28]. For in vivo measurements of protein synthesis, rats were given an intraperitoneal injection of $40 \mathrm{nmol} / \mathrm{g}$ puromycin hydrochloride (Enzo Life Sciences, NY, USA) dissolved in PBS. At exactly 30 min after injection, muscle tissue was extracted and frozen in liquid nitrogen for WB analysis.

\section{Determination of soleus dry weight}

In order to determine soleus dry weight, a part of the soleus muscle was weighed immediately after the dissection and then dried at $60^{\circ} \mathrm{C}$ for $48 \mathrm{~h}$. The dry weight was the same when measured $24 \mathrm{~h}$ and $48 \mathrm{~h}$ after the initiation of treatment, indicating that the sample was almost completely desiccated.

\section{Determination of the amount of total RNA and $28 S$ rRNA}

Total RNA was extracted from $10 \mathrm{mg}$ of frozen soleus muscle using a RNeasy Micro Kit (Qiagen, Hilden, Germany). RNA samples were treated by proteinase K and DNase I. RNA concentration was determined with spectrophotometer (Shimadzu, Japan) at $260 \mathrm{~nm}$. For storage, the aqueous solution of isolated RNA was frozen at $-84^{\circ} \mathrm{C}$. For reverse transcription to be provided, $1 \mu \mathrm{g}$ RNA, oligo(dT)15, random hexamers d(N)6, dNTPs, RNase inhibitor, and reverse transcriptase MMLV (60 min at $37^{\circ} \mathrm{C}$ ) were used. For each target RNA, $1 \mu \mathrm{l}$ cDNA was amplified in a $25 \mu \mathrm{l}$ SYBR Green PCR reaction containing Quantitect SYBR Green Master Mix (Syntol, Moscow, Russia) and $10 \mu \mathrm{M}$ of each primer: 5'-GAGATTCCCACTGTCCCTACCT-3' and 5'- GGCCTCCCACTTATTCTACACC-3' for Rn 28S; 5'-ACGGCAAGTTCAACGGCACAGTCAA-3' and 5'-GCTTTCCAGAGGGGCCATCCACA-3' for GAPDH; 5'-TCATGAAGTGTGACGTTGACATCC-3' and 5'-GTAAAACGCAGCTCAGTAACAGTC-3' for $\beta$-actin. The annealing temperature was based on the PCR primers' optimal annealing temperature. The amplification was monitored in a real time using the iQ5 multicolor real-time PCR detection system (Bio-Rad Laboratories, CA, USA). The identification of the PCR products was confirmed by melting-curve analysis after amplification. $\beta$-actin and GAPDH were used as the housekeeping genes. The amount of the total RNA was calculated by multiplying the RNA concentration by the total volume of RNA solution. This value was divided by the muscle weight to obtain $\mu \mathrm{g}$ of the total RNA per mg muscle.

\section{Western blot analysis}

The skeletal muscle tissue (30 mg) was homogenized in the ice-cold lysis buffer: $50 \mathrm{mM}$ Tris (pH 7.4), $150 \mathrm{mM} \mathrm{NaCl}, 1 \%$ Nonidet P-40, 0.5\% sodium deoxycholate, $0.1 \%$ SDS, $0.004 \%$ sodium azide, and $5 \mathrm{mM}$ EDTA, supplemented with $1 \mathrm{mM}$ DTT, $1 \mathrm{mM}$ PMSF, $10 \mu \mathrm{g} / \mathrm{ml}$ leupeptin, $5 \mu \mathrm{l} / \mathrm{ml}$ pepstatin and 1\% aprotinin (Sigma-Aldrich, MO, USA), mammalian protease inhibitor cocktail (Amresco, Solon, OH, USA), and phosphatase inhibitor cocktail B (Santa Cruz Biotechnology, CA, USA). The total protein concentration of the lysates was determined by incubation for $20 \mathrm{~min}$ at $4^{\circ} \mathrm{C}$ and centrifugation for $10 \mathrm{~min}$ at $12,000 \mathrm{~g}$. The protein content of the supernatants was quantified using an assay based on a modification of the Lowry protocol (RC DC Protein Assay; Bio-Rad Laboratories, Hercules, CA, USA). Bovine serum albumin was used as a standard. The samples were diluted in Laemmli buffer. The total protein (20-50 $\mu \mathrm{g})$ was subjected to SDS-PAGE [31], and the proteins were then transferred to nitrocellulose membrane (Bio-Rad Laboratories, CA, USA). Then, to verify equal loading of protein in all lanes, the nitrocellulose membrane was dyed by 
Ponceau S. The membranes were blocked for $1 \mathrm{~h}$ at room temperature with the blocking buffer (4\% nonfat milk powder; TBS, pH 7.4; and $0.1 \%$ Tween 20) and incubated overnight at $4{ }^{\circ} \mathrm{C}$ with primary antibodies (diluted in TBS-T) against 4E-BP1 (Thr37/46, 1:1000; Cell Signaling Technology, Beverly, MA, USA), p-p70s6k (Thr 389, 1:2000; Santa Cruz Biotechnology, p-AKT (Ser 473, 1:1000; Cell Signaling Technology, Beverly, MA, USA), p-GSK-3 $\beta$ (Ser 9, 1:1000; Cell Signaling Technology, Beverly, MA, USA), p-AMPK $\alpha 1 / 2$ (Thr 172, 1:10000; Santa Cruz Biotechnology, CA, USA), puromycin (1:3000; Kerafast Inc., Boston, MA, USA) and glyceraldehyde-3-phosphate dehydrogenase (GAPDH, 1:5000; Abcam, MA, USA). Three 10-min washes with TBS-T were then performed. After that, the membranes were incubated for $1 \mathrm{~h}$ at room temperature with horseradish peroxidase-conjugated secondary antibodies to rabbit or mouse immunoglobulins (diluted 1:200,000; Bio-Rad Laboratories, CA, USA). The membranes were then washed again in TBS-T 3 times for $10 \mathrm{~min}$ and incubated in Immun-Star HRP Chemiluminescent system (Bio-Rad Laboratories, Hercules, CA, USA). The protein bands were quantified using C-DiGit Blot Scanner (LI-COR Biotechnology, USA) and Image Studio Digits software. The signal from the protein bands was normalized to GAPDH. For protein synthesis detection, the measurements of the chemiluminescent signals were performed by determining the density of each whole lane with the entire molecular weight range of puromycin-labeled peptides.

\section{Statistical analysis}

All data are expressed as means \pm SEM. Significant differences between groups were statistically analyzed using one-way ANOVA followed by Tukey's test. Differences with values of $\mathrm{p}<0.05$ were considered to be statistically significant.

\section{Results}

\section{Changes in soleus wet and dry weight}

Alterations in soleus dry and wet weight as well as muscle weight-to-body weight ratio following 1-, 3- and 7 days of HS are shown in Table 1. The analysis of soleus dry weight allowed us to estimate the changes in the total protein content. A significant decrease in soleus dry and wet weight was observed after 3 and 7 days of $\mathrm{HS}(\mathrm{p}<0.05)$. The dry soleus

Table 1. Changes in soleus muscle weight and soleus weight-to-body weight ratio following 1-, 3and 7 days of HS. Values are means \pm SEM. Hindlimb suspension (HS) was performed for 1 (1HS), 3 (3HS), and 7 (7HS) days; $\mathrm{n}=7$ /group. ${ }^{*}$ - significant difference vs. Control, $\mathrm{p}<0.05$

\begin{tabular}{lllll}
\hline Group & $\begin{array}{l}\text { Soleus dry } \\
\text { weight, } \mathrm{mg}\end{array}$ & $\begin{array}{l}\text { Soleus dry weight, } \mathrm{mg} / \text { body } \\
\text { weight, } \mathrm{g}\end{array}$ & $\begin{array}{l}\text { Soleus wet weight, } \\
\mathrm{mg}\end{array}$ & $\begin{array}{l}\text { Soleus wet weight, mg / body } \\
\text { weight, g }\end{array}$ \\
\hline Control & $26 \pm 0,8$ & $0.1063 \pm 0,0029$ & $100.4 \pm 1.85$ & $0.415 \pm 0.0078$ \\
1HS & $25 \pm 1,1$ & $0.1095 \pm 0,0040$ & $96.4 \pm 2.84$ & $0.421 \pm 0.0104$ \\
3HS & $23 \pm 0,7^{*}$ & $0.1028 \pm 0,0031$ & $90.0 \pm 1.81^{*}$ & $0.403 \pm 0.0080$ \\
7HS & $16.7 \pm 0,5^{*}$ & $0.0722 \pm 0,0026^{*}$ & $65.8 \pm 0.98^{*}$ & $0.284 \pm 0.0049^{*}$ \\
\hline
\end{tabular}

Table 2. The amount of total RNA in rat soleus muscle following 1-, 3- and 7 days of HS. Values are means \pm SEM. Hindlimb suspension (HS) was performed for 1 (1HS), 3 (3HS), and 7 (7HS) days; $\mathrm{n}=7$ /group. ${ }^{*}$ - significant difference vs. Control, $\mathrm{p}<0.05$

\begin{tabular}{lll}
\hline Group & Total RNA, $\mu \mathrm{g}$ & Total RNA, $\mu \mathrm{g} /$ muscle tissue, mg \\
\hline Control & $132 \pm 14$ & $1.041 \pm 0.0909$ \\
1 HS & $65 \pm 4^{*}$ & $0.7082 \pm 0.0483^{*}$ \\
3 HS & $73 \pm 8^{*}$ & $0.792 \pm 0.0759^{*}$ \\
7 HS & $67 \pm 4^{*}$ & $0.8595 \pm 0.0464^{*}$ \\
\hline
\end{tabular}

Table 3. The amount of $28 \mathrm{~S}$ rRNA in rat soleus muscle following 1-, 3 - and 7 days of HS. Values are means \pm SEM. Hindlimb suspension (HS) was performed for 1 (1HS), 3 (3HS), and 7 (7HS) days; $n=7 /$ group. * - significant difference $v s$. Control, $\mathrm{p}<0.05$

\begin{tabular}{|c|c|}
\hline Group & $28 \mathrm{~S}$ rRNA, $2^{-\triangle \Delta C t}$ \\
\hline Control & $1 \pm 0.1$ \\
\hline $1 \mathrm{HS}$ & $0,772 \pm 0,112^{*}$ \\
\hline $3 \mathrm{HS}$ & $0.623 \pm 0.134^{*}$ \\
\hline 7HS & $0.361 \pm 0.152^{*}$ \\
\hline
\end{tabular}




\section{Cellular Physiology Cell Physiol Biochem 2016;39:1011-1020 \begin{tabular}{ll|l} 
DOI: 10.1159/000447808 & $\begin{array}{l}\text { O 2016 The Author(s). Published by S. Karger AG, Basel } \\
\text { www.karger.com/cpb }\end{array}$ \\
\cline { 2 - 3 }
\end{tabular} \\ Mirzoev et al.: Signaling Pathways Regulating Protein Synthesis in Rat Soleus during Unloading}

Fig. 1. Changes in the rate of protein synthesis in rat soleus muscle during hindlimb unloading. (A) Representative image of WB analysis for puromycin and Ponceau S staining to verify equal loading of proteins. (B) Quantification of the puromycin-labeled peptides, expressed as a percentage of the values obtained in the control group. $1 \mathrm{HS}$, $3 \mathrm{HS}, 7 \mathrm{HS}$, hindlimb suspension for 1, 3 and 7 days. ${ }^{*}$ - significant difference from control $(p<0.05)$. All values are means $\pm S E, n=7$ / group.

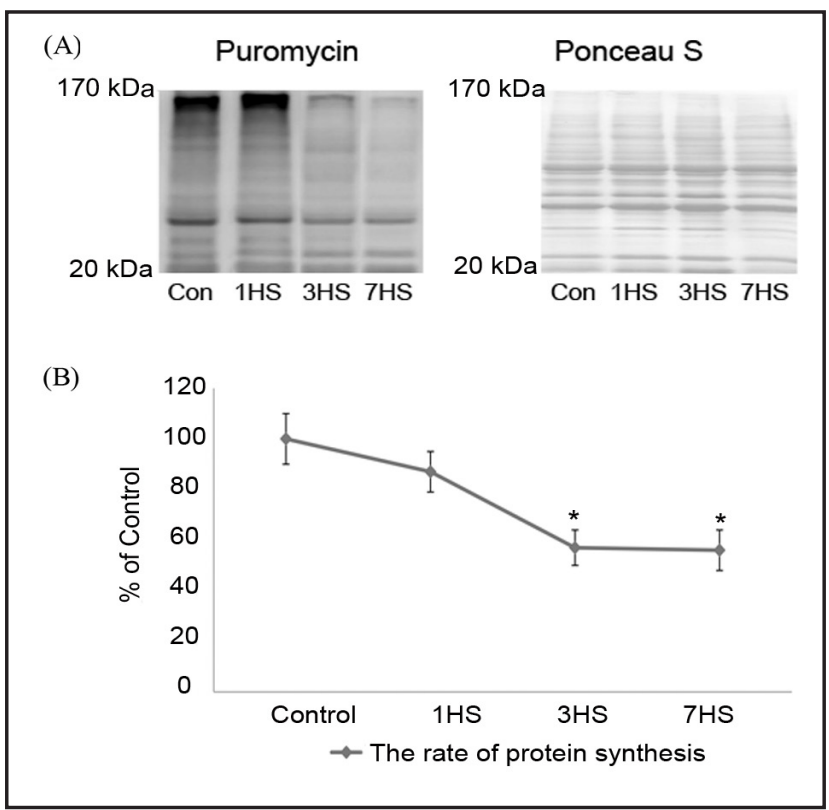

Fig. 2. Phosphorylation status of AKT and GSK-3 $\beta$ in rat soleus following hindlimb unloding. (A) Representative blots for $\mathrm{p}-\mathrm{AKT}$, t-AKT, p-GSK-3 $\beta$ and t-GSK-3 $\beta$. (B) Quantification of $\mathrm{p}-\mathrm{AKT} / \mathrm{t}-\mathrm{AKT}$ ratio and p-GSK-3 $\beta / \mathrm{t}-\mathrm{GSK} 3 \beta$ ratio expressed relative $(\%)$ to control. $1 \mathrm{HS}, 3 \mathrm{HS}$, 7HS, hindlimb suspension for 1,3 and 7 days. * - significant difference from control $(\mathrm{p}<0.05)$. All values are means $\pm \mathrm{SE}, \mathrm{n}=7$ /group.

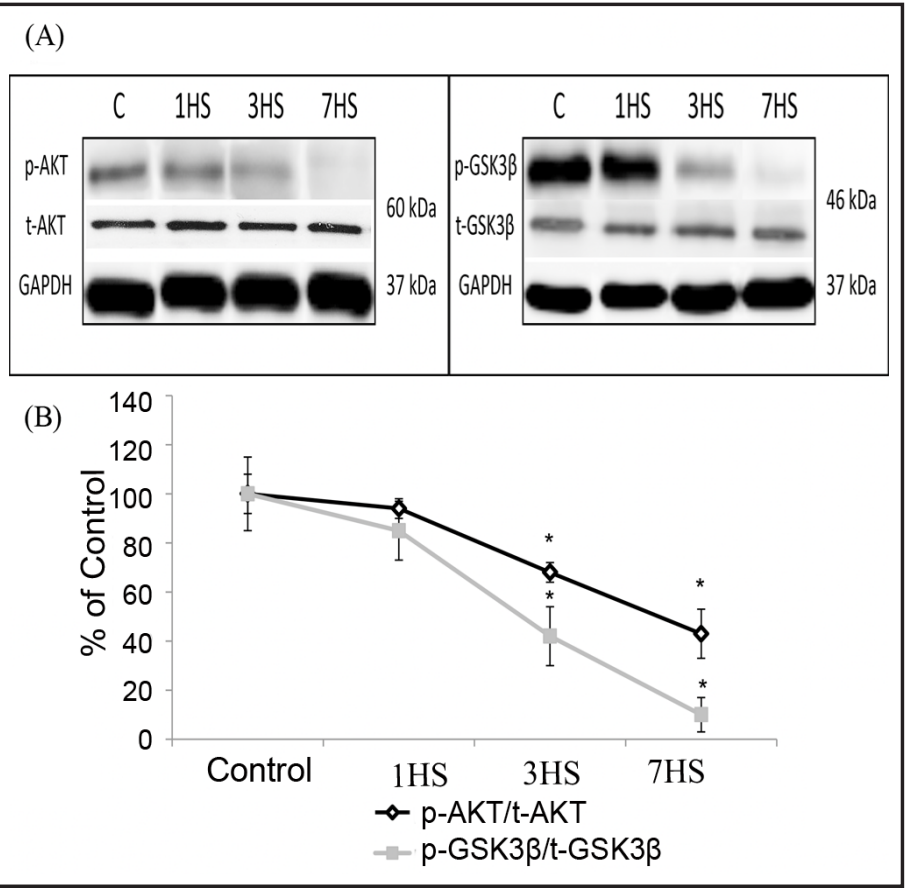

weight-to-body weight ratio was $32 \%$ reduced $(\mathrm{p}<0.05)$ after 7 -day HS as compared to control animals. The wet soleus weight-to-body weight ratio was also significantly $(p<0.05)$ diminished by the $7^{\text {th }}$ day of HS (Table 1 ).

The rate of protein synthesis

SUnSET measurements revealed a significant $43 \%$ and $44 \%(\mathrm{p}<0.05)$ decrease in the protein synthesis rate following 3 and 7 days of $\mathrm{HS}$, respectively (Fig. 1A,B).

\section{The amount of total RNA and $28 S$ rRNA}

HS for 1,3 and 7 days resulted in a significant reduction in both total RNA and total RNA per mg of tissue in soleus muscle (Table 2). RT-PCR revealed a significant decrease in the amount of 28S rRNA following 1, 3 and 7 days of HS as compared to control values. (Table 3 ). 
Fig. 3. Phosphorylation status of p70s6k and AMPK in rat soleus following hindlimb unloding. (A) Representative blots for p-p70s6k, t-p70s6k, p-AMPK and t-AMPK. (B) Quantification of $\mathrm{p}$ p70s6k/t-p70s6k ratio and p-AMPK/tAMPK ratio expressed relative (\%) to control. 1HS, 3HS, 7HS, hindlimb suspension for 1,3 and 7 days. * - significant difference from control $(\mathrm{p}<0.05)$. All values are means $\pm S E, n=7$ /group.

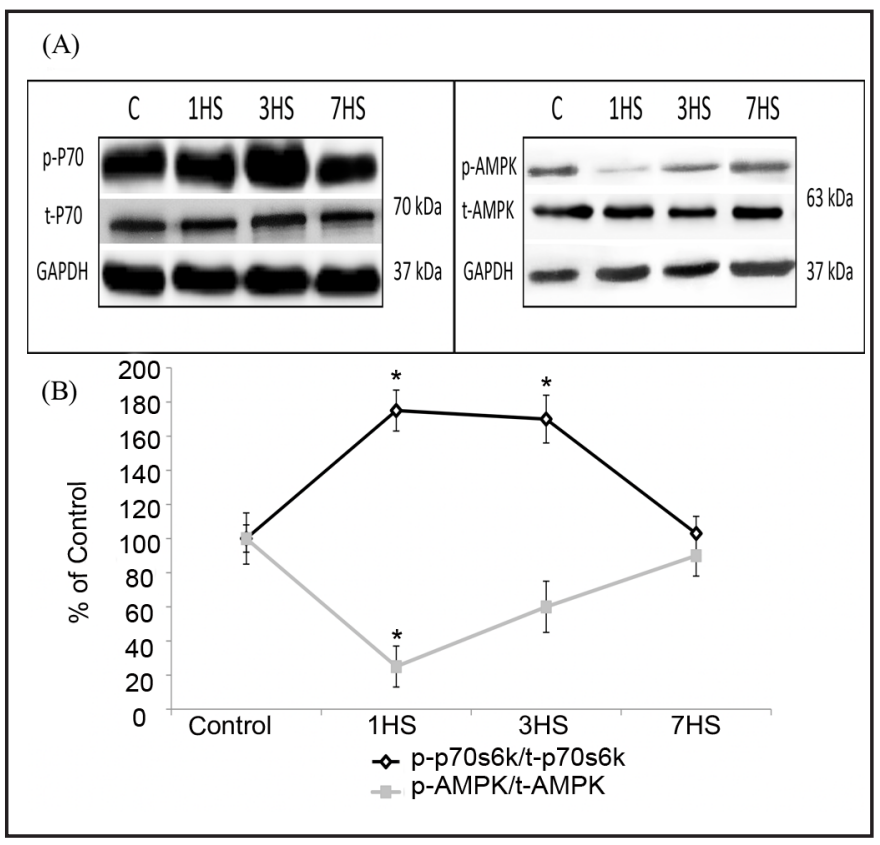

Fig. 4. Phosphorylation status of $4 \mathrm{E}-\mathrm{BP} 1$ in rat soleus following hindlimb unloding. (A) Representative blots for $\mathrm{p}-4 \mathrm{E}-\mathrm{BP} 1$ and $\mathrm{t}-4 \mathrm{E}-\mathrm{BP} 1$. (B) Quantification of $\mathrm{p}-4 \mathrm{E}-\mathrm{BP} 1 / \mathrm{t}-4 \mathrm{E}-\mathrm{BP} 1$ ratio expressed relative (\%) to control. $1 \mathrm{HS}, 3 \mathrm{HS}$, 7HS, hindlimb suspension for 1, 3 and 7 days. * - significant difference from control $(\mathrm{p}<0.05)$. All values are means $\pm S E, n=7$ /group.

(A)

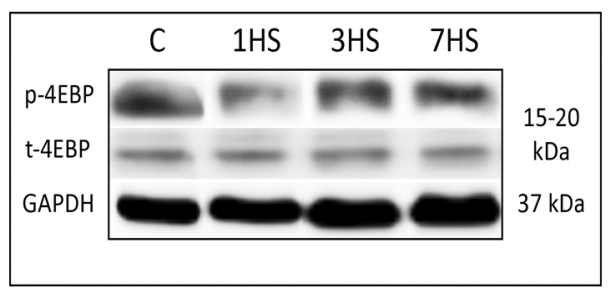

(B)

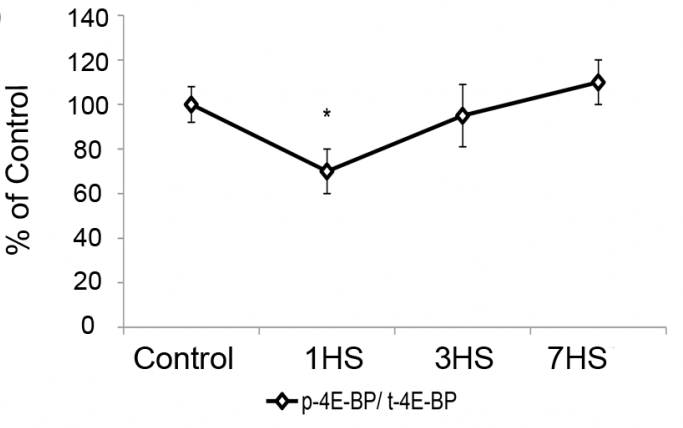

The phosphorylation status of the key signaling molecules involved in the regulation of protein synthesis

As shown in Figure 2 A,B, protein kinase B (AKT) phosphorylation level (p-AKT/t-AKT ratio) was significantly attenuated following 3 -day HS $(-32 \%, p<0.05)$ as well as 7 -day unloading $(-57 \%, \mathrm{p}<0.05)$. A similar response to HS was observed in $\mathrm{p}-\mathrm{GSK}-3 \beta / \mathrm{t}-\mathrm{GSK}-3 \beta$ ratio: a significant decrease after 3 days of HS $(-58 \%, \mathrm{p}<0.05)$ and a more dramatic $90 \%$ $(\mathrm{p}<0.05)$ decrease after 7-day HS (Fig. 2A,B).P-AMPK/t-AMPK ratio was significantly reduced $(-75 \%, \mathrm{p}<0.05)$ after 1-day hindlimb unloading (Fig. 3A,B). Surprisingly, 1- and 3-day HS resulted in a significant $75 \%$ and $70 \%(\mathrm{p}<0.05)$ increase in p-p70s6k/t-p70s6k ratio (Fig.3 $\mathrm{A}, \mathrm{B})$, whereas the level of 4E-BP1 phosphorylation was significantly downregulated $(-30 \%$, $\mathrm{p}<0.05$ ) within 24 hours of HS (Fig. 4A,B). 


\section{Discussion}

Our study was aimed at identifying the contribution of the various anabolic signaling pathways as well as ribosomal biogenesis to the protein synthesis rate in rat soleus muscle following the early stages of hindlimb unloading. We found a significant decline in the rate of protein synthesis in the soleus muscle after 3 and 7 days of unloading. We also observed a significant reduction in the soleus dry weight following 3- and 7-day HS, which could indicate that the content of total protein in soleus muscle was reduced. This result confirmed our previous data concerning the decreased protein content in rat soleus muscle after 7 and 14 days of HS [21]. It is obvious that the reduced protein content in soleus muscle could be caused by a decreased rate in protein synthesis and/or increased protein degradation. So, our data supported the hypothesis about the role of the decreased protein synthesis in the development of atrophy in rat postural muscles after 7 days of HS. Our data on the rate of protein synthesis are in agreement with the reports that have shown a decrease in protein synthesis rate in rat soleus following 3- [7], 4 [9] and 28 [8] days of HS. In these studies, using radioactive methods, Loughna et al. estimated the fractional rate of protein synthesis [7], and Fluckey et al. assessed the rate of protein synthesis in vitro [8,9]. The use of in vivo SUnSET technique, which was applied in our study, has shown a decrease in the protein synthesis rate in soleus muscle of mice after 7 days of hindlimb immobilization [32]. The general interest of our study was to identify the possible intracellular mechanisms/ pathways that could be implicated in a decline in protein synthesis rate in rat soleus by the $3^{\text {rd }}$ day of hindlimb unloading. First, we set out to assess several markers of ribosome biogenesis that is known to play an important role in the regulation of protein synthesis and skeletal muscle mass [18]. Therefore, we determined the levels of the total RNA, as well as the key rRNA (28S) of the large ribosomal subunit. We found a decrease in the content of both total RNA and 28S rRNA after 1-, 3- and 7-day HS. It is consistent with the report by Bajotto et al. about a significant drop in the levels of the total RNA and 28S rRNA in rat soleus after 6 days of HS [26]. It is well established, that proteinkinase mTORC1 is involved in the regulation of mRNA translation by phosphorylation of its downstream targets p70s6k and 4E-BP1 [11]. Surprisingly, we observed an increase in p70s6k phosphorylation after 1- and 3-day HS, although previously it had been shown a significant downregulation of p70s6k phosphorylation during longer periods of HS [19-22]. There is a growing body of evidence suggesting that mTOR-mediated p70s6k phosphorylation is not essential to sustain the normal maintenance of global protein synthesis. Kubica et al. reported that rapamycin does not affect the baseline rate of total protein synthesis in muscle [33]. Furthermore, myotubes derived from p70-s6k-null mice have normal fractional rates of protein synthesis and global translation initiation [34]. Moreover, Welle et al. showed that in an anti-myostatin-treated muscle rapamycin eliminated phosphorylation of p70s6k, but did not block the stimulation of myofibrillar protein synthesis [35].

The results of our study are supported by the recent study by You et al., who demonstrated that 3-day hindlimb immobilization decreases the global rate of protein synthesis in mouse soleus but activates mTOR signaling (the phosphorylated to total ratio of p70S6k (T389) was elevated) [32]. The authors of the above-mentioned paper consider this paradoxical maintenance of the mTORC1 activity and concurrent decline in protein synthesis as a physiological response compensating for the decreased muscle protein content. But what is the possible cause of such activation of mTORC1-signaling? We speculate that the maintenance of mTORC1 activity (phospho-p70s6k upregulation) during the early HS could be associated with the downregulation of AMPK phosphorylation that was observed in the present study. Moreover, our recent investigation has shown a significant decrease in AMPK phosphorylation in human soleus muscle following 3-day unloading (dry-immersion) [36]. It is known that AMPK can serve as an inhibitor of mTORC1 [14, 15, 37] and its upstream proteinkinases (PI3K and AKT) [37]. So, it is possible that a decrease in the level of AMPK phosphorylation could lead to mTORC1 activation and subsequent phosphorylation of p70s6k. Reduced 4E-BP1 phosphorylation was observed only after 1-day HS. In the literature 
there are discrepant data regarding the content of phospho-4E-BP1 in soleus muscle after unloading. Some studies did not reveal any changes in 4E-BP1 phosphorylation after 3 and 7 days of HS [38], while others reported a decrease in phospho-4E-BP1 content during longer periods of HS [19]. We speculate that the discrepancy between p70s6k and 4E-BP1 response to the early unloading could be associated with the different mTOR inputs to p70s6k and 4EBP1. It is also known that p70s6k activity can be regulated by both PI3K and mTOR signaling [39]. There is evidence that the PI3K and mTOR inputs to p70s6k can be separated. Deletion of an $\mathrm{N}$-terminal p70s6k fragment confers rapamycin resistance to the p70s6k protein, yet this truncation mutant remains sensitive to treatment with PI3K inhibitors [40, 41]. These data suggest that two separate inputs are required for p70s6k activation. Also, it has been demonstrated that the use of anti-myostatin antibody [35] as well as an overexpression of myostatin inhibitor Gasp-1 [42] increased p70s6 phosphorylation, but did not stimulate phosphorylation of 4E-BP1, which often increases in concert with p70s6k phosphorylation because both are phosphorylated by mTOR [35]. Moreover, Dreyer et al. as well as Jiang et al. showed that an increase in p70s6k phosphorylation can occur without a similar effect on $4 \mathrm{E}-\mathrm{BP} 1[43,44]$.

The decreased phosphorylation status of AKT and subsequently GSK-3 $\beta$ following 3 and 7 days of HS could lead to the inhibition of eIF2B, and, in turn, downregulate the initiation of cap-dependent translation. In addition, the inhibition of protein biosynthesis (at the level of translation elongation) in the unloaded soleus muscle could be linked to eEF2 hyperphosphorylation, which was earlier observed following 3-day HS [25].

Thus, the results of the present study suggest that a decrease in the rate of protein synthesis in rat soleus muscle following 3-and 7-day hindlimb unloading could be associated with a decreased amount of 28S rRNA, as well as reduced activity of mTORC1-independent AKT/GSK-3 $\beta$ signaling pathway.

\section{Acknowledgments}

The study was supported by the Russian Foundation for Basic Research (RFBR) grants No. 16-34-60055 and No. 15-04-05729.

\section{Disclosure Statement}

The authors confirm that there are no conflicts of interest.

\section{References}

1 Fitts RH, Riley DR, Widrick J: Physiology of a microgravity environment invited review: microgravity and skeletal muscle. J Appl Physiol 2000;89:823-839.

2 Bodine SC, Stitt TN, Gonzalez M, Kline WO, Stover GL, Bauerlein R, Zlotchenko E, Scrimgeour A, Lawrence JC, Glass DJ, Yancopoulos GD: Akt/mTOR pathway is a crucial regulator of skeletal muscle hypertrophy and can prevent muscle atrophy in vivo. Nature Cell Biology 2001;3:1014-1019.

3 Biolo G, Ciocchi B, Lebenstedt M, Barazzoni R, Zanetti M, Platen P, Heer M, Guarnieri G: Short-term bed rest impairs amino acid-induced protein anabolism in humans. J Physiol 2004;558:381-388.

4 Paddon-Jones D, Sheffield-Moore M, Cree MG, Hewlings SJ, Aarsland A, Wolfe RR, Ferrando AA: Atrophy and impaired muscle protein synthesis during prolonged inactivity and stress. J Clinic Endocrin Metabol 2006;91:4836-4841.

5 Lang SM, Kazi AA, Hong-Brown L, Lang CH: Delayed recovery of skeletal muscle mass following hindlimb immobilization in mTOR heterozygous mice. PLoS One DOI:10.1371/journal.pone.0038910. 
Mirzoev et al.: Signaling Pathways Regulating Protein Synthesis in Rat Soleus during Unloading

6 Kelleher AR, Kimball SR, Dennis MD, Schilder RJ, Jefferson LS: The mTORC1 signaling repressors REDD1/2 are rapidly induced and activation of p70S6K1 by leucine is defective in skeletal muscle of an immobilized rat hindlimb. Am J Physiol Endoc Metab 2013;304:229-236.

7 Loughna P, Goldspink G, Goldspink DF: Effect of inactivity and passive stretch on protein turnover in phasic and postural rat muscles. J Appl Physiol 1986;61:173-179.

8 Fluckey JD, Dupont-Versteegden EE, Montague DC, Knox M, Tesch P, Peterson CA, Gaddy-Kurten D: A rat resistance exercise regimen attenuates losses of musculoskeletal mass during hindlimb suspension. Acta Physiol Scand 2002;176:293-300.

9 Fluckey J, Dupont-Versteegden E, Knox M, Gaddy D, Tesch A, Peterson C: Insulin facilitation of muscle protein synthesis following resistance exercise in hindlimb-suspended rats is independent of a rapamycin sensitive pathway. Am J Physiol Endocrinol Metab 2004;287:1070-1075.

10 Hornberger T, Hunter R, Kandarian S, Esser K: Regulation of translation factors during hindlimb unloading and denervation of skeletal muscle in rats. Am J Physiol Cell Physiol 2001;281:179-187.

11 Kimball SR, Jefferson LS: Control of translation initiation through integration of signals generated by hormones, nutrients, and exercise. J Biol Chem 2010; 285:29027-29032.

12 Glass DJ: Signalling pathways that mediate skeletal muscle hypertrophy and atrophy. Nat Cell Biol 2003;5:87-90.

13 Hardt SE, Sadoshima J: Glycogen synthase kinase-3beta: a novel regulator of cardiac hypertrophy and development. J Circ Res 2002; 90:1055-1063.

14 Kimura N, Tokunaga C, Dalal S, Richardson C, Yoshino K, Hara K, Kemp BE, Witters LA, Mimura O, Yonezawa K: A possible linkage between AMP-activated protein kinase (AMPK) and mammalian target of rapamycin (mTOR) signalling pathway. Genes Cells 2003; 8:65-79.

15 Inoki K, Zhu T, Guan KL: TSC2 mediates cellular energy response to control cell growth and survival. Cell 2003b; 115:577-590.

16 Redpath NT, Foulstone EJ, Proud CG: Regulation of translation elongation factor-2 by insulin via a rapamycin-sensitive signaling pathway. EMBO J 1996;15:2291-2297.

17 McCarthy JJ, Esser KA: Anabolic and catabolic pathways regulating skeletal muscle mass. Curr Opin Clin Nutr Metab Care 2010;13:230-235.

18 Chaillou T, Kirby TJ, McCarthy JJ: Ribosome biogenesis: emerging evidence for a central role in the regulation of skeletal muscle mass. J Cell Physiol 2014;229:1584-1594.

19 Dupont E, Cieniewski-Bernard C, Bastide B, Stevens L: Electrostimulation during hindlimb unloading modulates PI3K-AKT downstream targets without preventing soleus atrophy and restores slow phenotype through ERK. Am J Physiol Regul Integr Comp Physiol 2001;300:408-417.

20 Gwag T, Lee K, Ju H, Shin H, Lee JW, Choi I: Stress and signaling responses of rat skeletal muscle to brief endurance exercise during hindlimb unloading: a catch-up process for atrophied muscle. Cell Physiol Biochem 2009;24:537-546.

21 Lysenko EA, Turtikova OV, Kachaeva EV, Ushakov IB, Shenkman BS: Time course of ribosomal kinase activity during hindlimb unloading. Dokl. Biochem. Biophys 2010;434:223-226.

22 Sugiura T, Abe N, Nagano M, Goto K, Sakuma K, Naito H, Yoshioka T, Powers SK: Changes in PKB/Akt and calcineurin signaling during recovery in atrophied soleus muscle induced by unloading. Am J Physiol Regul Integr Comp Physiol 2005; 288:1273-1278.

23 Van der Velden JL, Langen RC, Kelders MC, Willems J, Wouters EF, Janssen-Heininger YM, Schols AM: Myogenic differentiation during regrowth of atrophied skeletal muscle is associated with inactivation of GSK-3beta. Am J Physiol Cell Physiol 2007;292:1636-1644.

24 White JR, Confides AL, Moore-Reed S, Hoch JM, Dupont-Versteegden EE: Regrowth after skeletal muscle atrophy is impaired in aged rat, despite similar responses in signaling pathways. Exp Gerontol 2015;64:1732.

25 Krasniy AM, Lysenko EA, Kozlovskaya IB, Shenkman BS, Lomonosova YN: Phosphorylation of elongation factor and its kinase expression in rat m.soleus under early stage of hindlimb unloading. Dokl Biochem Biophys 2013;453:283-285.

26 Bajotto G, Sato Y, Kitaura Y, Shimomura Y: Effect of branched-chain amino acid supplementation during unloading on regulatory components of protein synthesis in atrophied soleus muscles. Eur J Appl Physiol 2011;111:1815-1828. 
Mirzoev et al.: Signaling Pathways Regulating Protein Synthesis in Rat Soleus during Unloading

27 Morey-Holton E, Globus R: Hindlimb unloading rodent model: technical aspects. J Appl Physiol 2002;92:1367-1377.

28 Goodman C, Mabrey D, Frey J, Miu M, Schmidt E, Pierre P, Hornberger T: Novel insights into the regulation of skeletal muscle protein synthesis as revealed by a new nonradioactive in vivo technique. FASEB J 2011;25:1028-1039.

29 Nathans D: Puromycin Inhibition of Protein Synthesis: Incorporation of Puromycin into Peptide Chains. Proc Natl Acad Sci USA 1964;51:585-592.

30 Schmidt EK, Clavarino G, Ceppi M, Pierre P: SUnSET, a nonradioactive method to monitor protein synthesis. Nat Methods 2009;6:275-277.

31 Laemmli UK: Cleavage of structural proteins during the assembly of the head of bacteriophage T4. Nature 1970;227:680-685.

32 You JS, Anderson GB, Dooley MS, Hornberger TA: The role of mTOR signaling in the regulation of protein synthesis and muscle mass during immobilization. Dis Model Mech 2015;8:1059-1069.

33 Kubica N, Bolster DR, Farrell PA, Kimball SR, Jefferson LS: Resistance exercise increases muscle protein synthesis and translation of eukaryotic initiation factor 2Bepsilon mRNA in a mammalian target of rapamycin-dependent manner. J Biol Chem 2005;280:7570-7580.

34 Mieulet V, Roceri M, Espeillac C, Sotiropoulos A, Ohanna M, Oorschot V, Klumperman J, Sandri M, Pende M: S6 kinase inactivation impairs growth and translational target phosphorylation in muscle cells maintaining proper regulation of protein turnover. Am J Physiol Cell Physiol 2007;293:712-722.

35 Welle S, Burgess K, Mehta S: Stimulation of skeletal muscle myofibrillar protein synthesis, p70 S6 kinase phosphorylation, and ribosomal protein S6 phosphorylation by inhibition of myostatin in mature mice. Am J Physiol Endocrinol Metab 2009;296:567-572.

36 Vilchinskaya NA, Mirzoev TM, Lomonosova YN, Kozlovskaya IB, Shenkman BS: Human Muscle Signaling Responses to 3-Day Head-out Dry Immersion. J Musculoskel Neuron Interact 2015;15:286-293.

37 Bolster DR, Crozier SJ, Kimball SR, Jefferson LS: AMP-activated protein kinase suppresses protein synthesis in rat skeletal muscle through down-regulated mammalian target of rapamycin (mTOR) signaling. J Biol Chem 2002;277:23977-80.

38 Cannavino J, Brocca L, Sandri M, Bottinelli R, Pellegrino MA: PGC1- $\alpha$ over-expression prevents metabolic alterations and soleus muscle atrophy in hindlimb unloaded mice. J Physiol 2014;592:4575-4589.

39 Thomas G, Hall MN: TOR signalling and control of cell growth. Curr Opin Cell Biol 1997;9:782-787.

40 Mahalingam M, Templeton DJ: Constitutive activation of S6 kinase by deletion of amino-terminal autoinhibitory and rapamycin sensitivity domains. Mol Cell Biol 1996;16:405-413.

41 Dennis PB, Pullen N, Kozma SC, Thomas G: The principal rapamycin-sensitive p70(s6k) phosphorylation sites, T-229 and T-389, are differentially regulated by rapamycin-insensitive kinase kinases. Mol Cell Biol 1996;16:6242-6251.

42 Brun C, Périé L, Baraige F, Vernus B, Bonnieu A, Blanquet V: Absence of hyperplasia in Gasp-1 overexpressing mice is dependent on myostatin up-regulation. Cell Physiol Biochem 2014;34:1241-1259.

43 Dreyer HC, Glynn EL, Lujan HL, Fry CS, DiCarlo SE, Rasmussen BB: Chronic paraplegia-induced muscle atrophy downregulates the mTOR/S6K1 signaling pathway. J Appl Physiol 2008;104:27-33.

44 Jiang YP, Ballou LM, Lin RZ: Rapamycin-insensitive regulation of 4e-BP1 in regenerating rat liver. J Biol Chem 2001;276:10943-10951. 